Article

\title{
LNG and Cruise Ships, an Easy Way to Fulfil Regulations-Versus the Need for Reducing GHG Emissions
}

\author{
Elizabeth Lindstad *(D) and Agathe Rialland \\ SINTEF Ocean, Marine Technology Centre, 7465 Trondheim, Norway; agathe.rialland@sintef.no \\ * Correspondence: Lindstad@sintef.no
}

Received: 30 January 2020; Accepted: 5 March 2020; Published: 8 March 2020

check for updates

\begin{abstract}
Liquified natural gas (LNG), with its low sulphur content, its favorable hydrogen-to-carbon ratio, and the lower nitrogen oxide emission when combusted compared to conventional fuels, fulfils all International Maritime Organization (IMO) air emission regulations. For the cruise industry, with their large number of customers and their high public visibility, LNG has therefore become a tempting option for new cruise ships. However, larger well-to-tank (WTT) emissions for the LNG supply chain as well as un-combusted methane $\left(\mathrm{CH}_{4}\right)$ from the ship's engine might more than nullify any greenhouse gas (GHG) gains. Previous studies have shown very different GHG impacts from the use of LNG as a ship fuel. With climate change potentially being the largest threat to mankind, it is important that decisions with an impact on future GHG emissions are based on the best available knowledge within a sector and across sectors. The motivation for this study has therefore been to establish comparable GHG estimates for well-to-wake (WTW) emissions for LNG and traditional fuels in a transparent way. The results show that there is a need for adopting policies that can reduce the broader GHG emissions of shipping instead of $\mathrm{CO}_{2}$ only, including the well-to-tank emissions of ship fuels. If not, we might end up with a large number of ships with GHG savings on paper only, while the real GHG emissions increases.
\end{abstract}

Keywords: maritime transport; alternative fuels; LNG; GHG; EEDI; IMO

\section{Introduction}

Due to its favorable hydrogen-to-carbon ratio, liquified natural gas (LNG) is often seen as a tempting option to reduce maritime greenhouse gas (GHG) emissions. The explanation is that, in theory, by using emission and energy coefficients in combustion only, LNG results in about $25 \%$ lower GHG emissions than conventional fuels like diesel (MGO, marine gas oil) or bunker oil (HFO, heavy fuel oil), in terms of tank-to-wake emissions (TTW). When the first development of LNG for maritime applications started in the late 1980s, the focus was on the need for reducing local pollution and improving air quality, and not on GHG reductions. The advantage of LNG was its very low sulphur content and the reduction in nitrogen oxide and particles emitted when combusted, compared to conventional fuels.

The first regulation of sulphur oxides $\left(\mathrm{SO}_{\mathrm{x}}\right)$ and nitrogen oxides $\left(\mathrm{NO}_{\mathrm{x}}\right)$ emissions came in 1997, when the International Maritime Organization (IMO) added Annex VI to the International Convention for the Prevention of Pollution from Ships [1]. Back then, the requirements were mild and could easily be met by conventional fuels and engine technologies. The same year, GHG emissions came on the IMO agenda as a result of the Kyoto Protocol [2]. However, it took IMO another 14 years before the regulation of GHG through the Energy Efficiency Design Index (EEDI) was adopted as part of the MARPOL Convention by the Resolution MEPC.203 (62) [3]. The EEDI sets ship-specific limits for $\mathrm{CO}_{2}$ emissions for ships built from 2013 and onwards. 
Considering LNG from an EEDI perspective, neither the larger well-to-tank (WTT) emissions for the LNG supply chain, nor uncombusted methane $\left(\mathrm{CH}_{4}\right)$ from the ship's engine, which might more than nullify any GHG gains, are relevant. The explanation is as follows. First, the WTT emissions are out of scope, since the EEDI only focuses on fuel consumption on the vessel, i.e., tank-to-wake (TTW). Second, since $\mathrm{CO}_{2}$ is the only GHG gas included in the EEDI formula, uncombusted methane, which is a GHG gas trapping 85 times more heat than $\mathrm{CO}_{2}$ over a 20 year period [4], makes no impact on the EEDI assessment. Metrics that weight emitted (exhaust) gases according to their global warming potential (GWP), to report them in terms of " $\mathrm{CO}_{2}$ equivalents" $\left(\mathrm{CO}_{2} \mathrm{eq}\right)$ have become standard currency to benchmark and communicate the relative and absolute contributions to climate change [5]. GWP is usually integrated over 20 or 100 years.

Given the EEDI thresholds for phase 3 (coming into force from 2022 to 2025), i.e., a 30\% reduction in fuel consumption for most vessel types compared to the vessels built during the reference period 1998-2008, simply selecting an LNG compliant engine including the fuel system will in practice satisfy the requirements, even if it might not give any GHG reductions at all. There are two LNG engine options: a pure gas engine where the gas is spark-ignited, or a dual-fuel engine that can run either on LNG ignited by a small amount of diesel, or purely on conventional fuels such as diesel. In practice, with LNG being available in a limited number of ports, dual-fuel engines will be the main option for ships used in global operations. Regarding the IMO regulations, both these LNG engine types fulfil IMO Tier III NO $\mathrm{NO}_{x}$ requirements, which are applicable for new ships built from 2016 onwards in US and Canadian waters and from 2021 in the European Emission Control Area (ECA) (North Sea and the Baltic). With its very low sulphur content, LNG also fulfils both the global sulphur cap $(0.5 \% \mathrm{~S})$ and the $0.1 \% \mathrm{~S}$ cap in the ECAs. To summarize, when LNG is chosen as the fuel for a new cruise vessel or any other newbuilt vessels, it fulfils all the IMO air emission regulations.

In 2010, the Global Anthropogenic GHG emissions added up to 52 billion tons of $\mathrm{CO}_{2}$ eq [4], measured with a 100 year time horizon (GWP100), for which $\mathrm{CH}_{4}$ accounted for $20 \%$, as shown in the right part of Figure 1. In comparison, $\mathrm{CO}_{2}$ from fossil fuel and industrial processes $\left(\mathrm{CO}_{2}\right)$, plus from forest and other land used $\left(\mathrm{CO}_{2} \mathrm{FOLU}\right)$, accounted for $73 \%(62 \%+11 \%)$. The remaining $7 \%$ came from nitrous oxide $\left(\mathrm{N}_{2} \mathrm{O}\right)$ and from fluorinated gases. Unlike $\mathrm{CO}_{2}$, which stays in the atmosphere for hundreds of years, the impact of $\mathrm{CH}_{4}$ emissions is largest during the first decades. With the urgent need to reduce global GHG emissions [4], there is a strong argument for focusing also on the short-term impact of the individual GHG gases over the next 20 years [6], as illustrated in the left side of Figure 1 based on Intergovernmental Panel on Climate Change (IPCC) report 2013 [7].

\section{Global GHG emissions - GWP20}

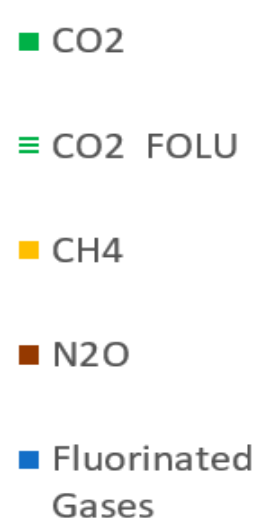

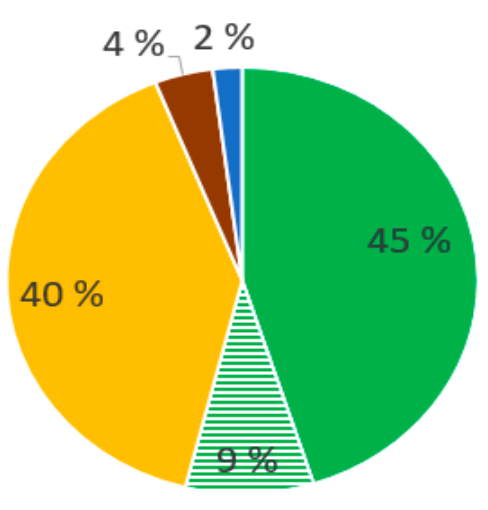

GWP100

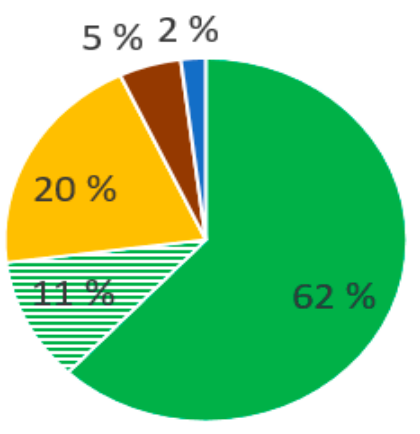

Figure 1. Global greenhouse gas (GHG) emissions shares in 2010: Applying the estimated global warming potential (GWP) of each GHG in $\mathrm{CO}_{2}$ equivalents for 20 and 100 years, respectively (assuming fluorinated gases share are constant). Source: authors. 
Basically, the difference between using GWP20 instead of GWP100 is that the impact of $\mathrm{CH}_{4}$ increases by $100 \%$, from $20 \%$ to $40 \%$ of the total GHG's emitted. Moreover, the smaller size of the GWP100 pie compared to the GWP20 pie illustrates that, when 2010 emissions are calculated based on GWP20, the total adds up to around 70 billion tons of $\mathrm{CO}_{2} \mathrm{eq}$, compared to 52 billion with GWP100.

With this large GHG impact of $\mathrm{CH}_{4}$ emissions, one may wonder why methane has not yet been regulated by IMO. This question is even more obvious given the following facts:

1. Methane slip is a recognized challenge when LNG is used as a fuel.

2. While LNG 20 years ago gave large reductions in local pollution compared to conventional fuels, the much stricter air emission regulation, coming into effect from 2015 to 2021, has reduced the emission reduction potential of LNG as a ship fuel with more than $80 \%$ compared to conventional fuels both for $\mathrm{NO}_{\mathrm{x}}$ and $\mathrm{SO}_{\mathrm{x}}$.

3. In sensitive areas with a need for reducing emissions even bellow ECA requirements, state-of-the-art engine technology in combination with hybrid scrubbers or synthetic diesel (made from natural gas) can today deliver nearly similar performance as LNG.

Moreover, in the absence of methane slip regulations, the following facts would be strong drivers for increased use of LNG:

1. The LNG engine solution available for cruise and other ocean-going vessels using 4 stroke engines tends to come at a lower capex than alternative abatement options to fulfil IMO air emission regulations from 2020 [8].

2. LNG is less expensive than MGO and is now, in some regions, becoming even cheaper than HFO [9].

3. For the cruise industry, with its high public visibility, it is tempting to choose LNG as a fuel just due to its good reputation in the public opinion.

The main reason why methane slip has not yet been regulated might be that previous studies have shown very different GHG impacts from the use of LNG, and that the regulators so far have given most importance to the studies showing favorable well-to-wake (WTW) emissions for LNG compared to traditional fuels. With climate change potentially being the largest threat to mankind, as stated in the Paris agreement adopted at the COP21 in 2015 [10], it is important that decisions with impact on future GHG emissions are based on best available knowledge within a sector and across sectors. The motivation for this study has therefore been to establish comparable GHG estimates for WTW emissions for LNG and traditional fuels in a transparent way. This is to ensure that both regulators and the shipping sector take decisions about future fuels based on best available knowledge, rather than on mainstream perceptions that might be proven wrong afterwards.

This article starts with an introduction of the challenge at hands (this Section). The study materials and method are described in Section 2. The main analysis and results are presented in Section 3. In Section 4, the results from this study are compared with previous studies, and Section 5 presents the conclusions and the results' impact on Policy.

\section{Materials and Methods}

A systematic review of previous studies was performed, based on a comprehensive search and analysis of published studies on alternative fuels for shipping in addition to general studies focusing on LNG. Some of these studies included more than conventional fuels and LNG, for example biofuels, methanol, liquid petroleum gas (LPG), and hydrogen. Independently of this, the results reported here include only the fuels in focus for this study: conventional fuels and LNG. While the tank-to-wake (TTW) emissions from LNG combustion in each engine are consistent regardless of the source of the LNG, the well-to-tank (WTT) emissions can vary widely across LNG sources. Today, maritime transport consumes around 300 million tons of fuel, of which diesel and bunker oil (MGO, VLSFO very-low sulphur fuel oil $<0.5 \%$ sulphur, HFO) account for more than $95 \%$. This means that the shipping sector 
only consumes a very small share of the around 400 million tons of LNG produced annually. For these reasons, a significant number of studies focusing on LNG production independently of its final consumer was included in the present study.

Previous studies of maritime fuels vary in goal and scope, but the majority are tank-to-wake (TTW) studies (also called tank-to-propeller), which only focus on assessing the impacts of the combustion of marine fuels. Typically, these studies have focused on existing Emission Control Areas (ECAs) such as in the North Sea and the Baltic, and their potential extensions [11-16]. Less attention has been given to the climate impact of the 2020 global sulphur cap $[17,18]$ and the stricter $\mathrm{NO}_{\mathrm{x}}$ regulations [16]. There are only a few full LCA-studies (Life Cycle Assessment) of maritime fuels $[19,20]$. Instead, complexity is often reduced by excluding the construction and decommissioning phase for the oil and gas chains from source through processing and refining. This is a typical approach in well-to-wake (WTW) studies, which include the production of the energy in addition to the TTW emissions $[9,13,17,19,21-32]$.

In this study, a three-step approach was used to establish the WTW emissions of LNG versus conventional fuels: first, establishing the WTT emissions based on a literature study; second, setting up engine performance figures as a function of fuel and engine technology, including methane slip, based on literature and in-house knowledge; third, establishing WTW emissions combining 1 and 2.

\section{Results and Analysis}

This section contains the following subsections: WTT emissions; engine performance including methane slip; WTW emissions.

\subsection{Well-to-Tank (WTT)}

Well-to-tank emissions include all emissions from the production of the fuels and the transport needed to deliver them into the ships' fuel tanks. For a conventional fuel, it includes oil production, processing and transport to the refinery, oil refining at the refinery, transport to the ship, and bunkering operation. For LNG, it includes gas production, processing and pipeline transport, gas liquefaction to LNG, LNG terminals, and transport. Table 1 contains the WTT emissions from previous studies. The first column gives the fuel type; the second is used as an identifier to link the line to a specific organization or author of the actual study; the third column gives the reference to the study. Columns four to seven show gram $\mathrm{CO}_{2}$ eq per MJ (megajoule), first for GWP100, followed by min and max figures for GWP100, then GWP20 values. A blank field for a study means that it has not published the respective value.

In Table 1, we have defined six (6) different Id to link publications to organizations and researchers associated to that organization. The purpose of this is to make it easier to read and compare the values for the investigated fuels, i.e., HFO, VLSFO, MGO, LNG. A short presentation of the six groups of studies is given below:

Id (1) is used for Thinkstep [31], for which we quote "Thinkstep has created the world's leading Life Cycle Assessment software and databases for use across all business sectors" [33]. In addition, the WTT emission values in the Thinkstep (2019) study were thoroughly discussed with the participating oil and gas companies.

Id (2) is used for the study: Increased Use of LNG might not reduce Maritime GHG emissions, by Lindstad (2019) [32]. This study was performed to understand the assumptions, hypotheses, and limitations in the Thinkstep (2019) study and their significantly high estimates of well-to-wake GHG savings.

Id (3) is used for the International Council of Clean Transports study: The climate implications of using LNG as a marine fuel (ICCT, 2020) [9]. In their analysis, they used the GREET [34] model from Argonne National Laboratory to estimate upstream emissions for LNG and conventional marine fuels. GREET is an acronym for Greenhouse gases; Regulated Emissions, and Energy use in Transportation. It is used by government agencies, industries, and academia, because it is transparent, flexible, and contains high-quality data. 
Id (4) is used for the literature review of previous WTT studies performed as part of the ICCT 2020 study [9].

Id (5) is used for studies performed by Verbeek and TNO [23,28]. They illustrate how research groups gradually have put more focus and weight on methane slips both in the WTT and the TTW part, instead of performing the calculations based on best-case assumptions. For example, from 2011 to 2015, the LNG figures published by Verbeek and TNO increased from 10.7 to $19 \mathrm{~g} \mathrm{CO}_{2}$ eq per MJ, the latter being within the same range as published by JRC-Eucar-Concawe in 2014 [25].

Id (6) is used for studies and publications by DNV GL [24,35,36], the latest through their Maritime Outlook 2050 and their Alternative fuel studies, both from 2019. Their studies are generally well known within the maritime community.

Table 1. Well-to-tank (WTT) emissions from previous studies in gram $\mathrm{CO}_{2}$ eq per MJ, outlined as global warming potential for 100 and 20 years (GWP100 and GWP20).

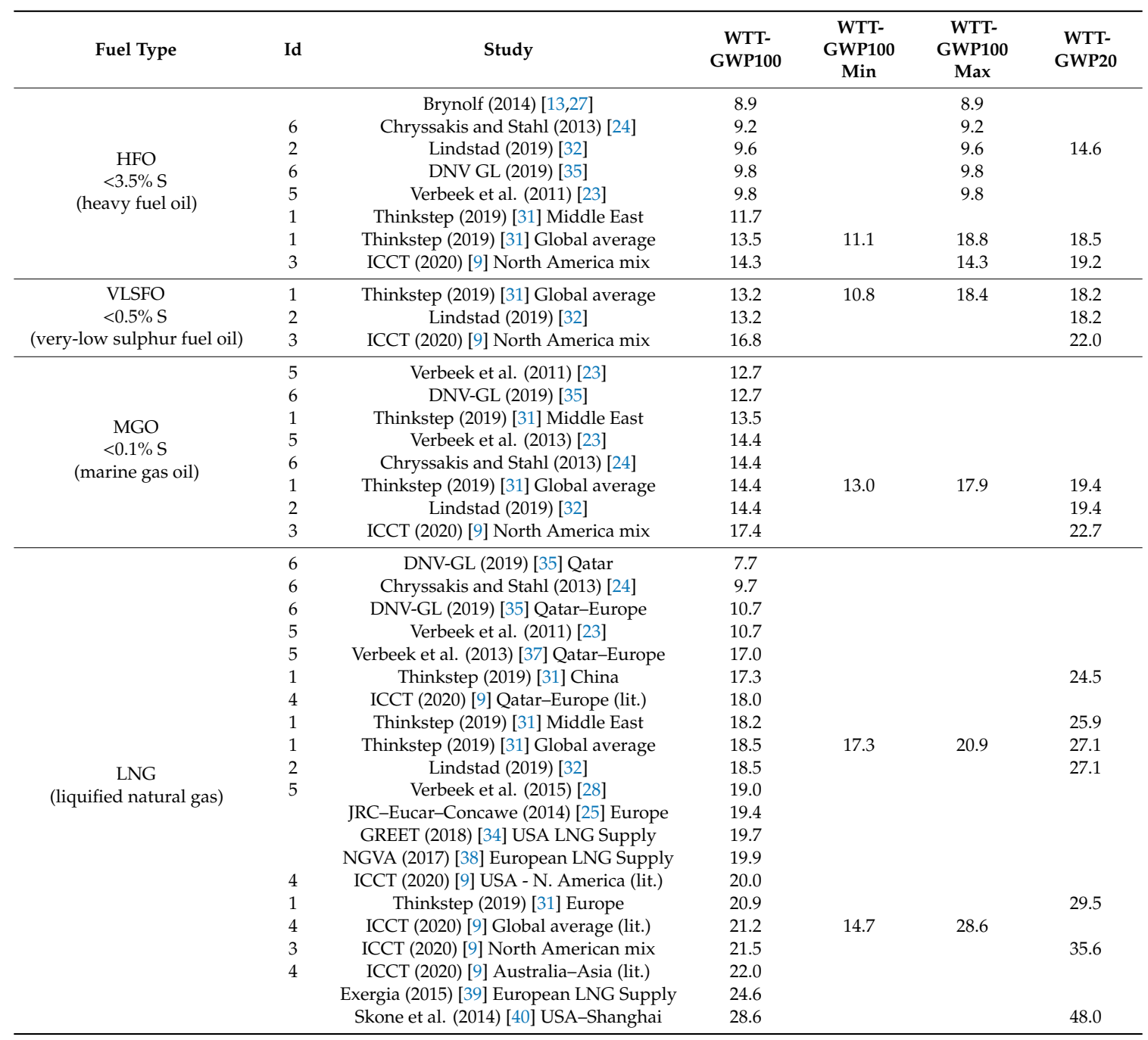

Reading the table, the first observation is that interpreting and explaining all the different values could have been a study on its own. However, there are some clear trends and gaps among the reported figures. Starting with HFO, the difference is mainly caused by different allocation principles between the mix of products coming out of the refinery. Allocation based on weight, energy, process complexity, or sales price for each of the main products such as Nafta, Petrol, diesel are examples of allocation models. For more insight on allocation principles, see [31,41]. An alternative approach is that desulfurizing residual fuel oils implies cost and complexity, like conversion from residual to 
distillate. This means that conversion from HFO to diesel costs up to $10-15 \%$ of the energy content in the HFO [42,43]. With new modern refineries set up to convert all crude into higher-priced products, HFO will from 2020 come from existing refineries as the bottom-of-the-barrel product, like a waste product with no energy usage to add to it. Following this approach fully displays the theoretical energy saving of using HFO and scrubbers instead of producing compliant fuel at the refinery.

For VLSFO $<0.5 \%$, which is a low sulphur heavy fuel oil, there are few studies available. VSLFO (very-low sulphur fuel oil) can either be made as a blend or straight out of a very modern refinery. Thinkstep (2019) [31] indicates that it comes at around $90 \%$ of $\mathrm{CO}_{2}$ eq per MJ compared to MGO. This might be in the low end compared to Shell (2016) [42] and Lindstad et al. (2017) [43]. Anyhow, if we base the calculation on blending MGO with HFO to deliver a product meeting the $0.5 \%$ sulphur cap, the calculation becomes (with $25 \%$ of HFO with less than $2.5 \% \mathrm{~S}$ content and $75 \% \mathrm{MGO}$ ): $9.6 * 0.25+$ $14.4 * 0.75=13.4 \mathrm{~g}$ of $\mathrm{CO}_{2}$ eq per MJ.

For MGO, which is a diesel, most studies display values in the range from 12.7 to $14.4 \mathrm{~g}$ of $\mathrm{CO}_{2} \mathrm{eq}$ per MJ, apart from the ICCT (2020) study [9] displaying a value of 17.4. The explanation for the high ICCT value is that it is based on a high share of US crude in combination with refining at a modern US refinery built to produce no bunker oils. Full conversion of all crude to distillates and chemical feedstock comes at a high energy cost compared to a traditional refinery, where the bottom of the barrel becomes HFO, pet-coke, and asphalt [42,43]. Moreover, the ICCT figures are in line with the North America figure of 17.9 by Thinkstep (2019) [31], which, anyhow, are much higher than the Thinkstep figures for the rest of the world (13-13.5).

For LNG, apart from a few out-layers, the values are in the range from 17 to $22 \mathrm{~g}$ of $\mathrm{CO}_{2}$ eq per MJ. Moreover, Thinkstep (2019) [31] shows regional values in the range from 17.3 to 20.9. ICCT (2020) [9] shows $21.2 \mathrm{~g}$ of $\mathrm{CO}_{2}$ eq per MJ as global average based on their literature study, with the lowest study at 14.7 ignoring the methane slip and the highest at 28.6 given by a large methane slip. In comparison, the Thinkstep (2019) [31] global average of $18.5 \mathrm{~g}$ of $\mathrm{CO}_{2}$ eq per MJ for LNG consists of $13.7 \mathrm{~g}$ of $\mathrm{CO}_{2}$, $4.7 \mathrm{~g}$ of $\mathrm{CO}_{2}$ eq from $\mathrm{CH}_{4}$ and $0.1 \mathrm{~g}$ of $\mathrm{CO}_{2} \mathrm{eq}$ from $\mathrm{N}_{2} \mathrm{O}$ (methane slip then accounts for $25 \%$ of the GHG emissions (GWP100)). With a shorter time horizon, i.e., GWP20, the Thinkstep (2019) [31] value adds up to $27.1 \mathrm{~g}$ of $\mathrm{CO}_{2}$ eq per $\mathrm{MJ}$, of which methane slip accounts for 13.3 , i.e., nearly $50 \%$ of the GHG emissions. ICCT (2020) displays 35.4 as their GWP20 value.

While there are good reasons for some variations between the figures found in the individual studies, what is needed to make sound WTW comparisons between the individual fuels are the relative differences between the fuels. Table 2 shows the relative differences in gram(s) of $\mathrm{CO}_{2}$ eq per MJ based on Thinkstep 2019 [31] figures for the Middle East, representing the largest oil- and gas-producing region in the world, the Thinkstep Global average, Lindstad 2019 [32] and ICCT (2020) [9]. From this point forward, MGO is kept as the reference fuel so that all relative differences are quoted versus MGO.

Table 2. GHG emissions differences between alternative fuels and studies (GWP100).

\begin{tabular}{|c|c|c|c|c|c|c|}
\hline & $\begin{array}{c}\text { Thinkstep } \\
\text { (2019) [31] } \\
\text { North America }\end{array}$ & $\begin{array}{l}\text { Thinkstep } \\
\text { (2019) [31] } \\
\text { Middle East }\end{array}$ & $\begin{array}{c}\text { Thinkstep } \\
\text { (2019) [31] } \\
\text { Global Average }\end{array}$ & $\begin{array}{c}\text { Lindstad } \\
\text { (2019) [32] }\end{array}$ & $\begin{array}{c}\text { ICCT } \\
(2020)[9]\end{array}$ & GWP100 \\
\hline LNG & 18.9 & 18.2 & 18.5 & 18.5 & 21.5 & gram of $\mathrm{CO}_{2}$ eq per $\mathrm{MJ}$ \\
\hline MGO & 17.9 & 13.5 & 14.4 & 14.4 & 17.4 & gram of $\mathrm{CO}_{2}$ eq per $\mathrm{MJ}$ \\
\hline $\mathrm{HFO}$ & 18.8 & 11.7 & 13.5 & 9.6 & 14.3 & gram of $\mathrm{CO}_{2}$ eq per $\mathrm{MJ}$ \\
\hline LNG/MGO & & $135 \%$ & $128 \%$ & $128 \%$ & $124 \%$ & \\
\hline LNG/HFO & & $156 \%$ & $137 \%$ & $193 \%$ & $150 \%$ & \\
\hline
\end{tabular}

The main observations from Table 2 are: first, that the relative differences between the individual studies regarding LNG is smaller than the variance for MGO; second, when we divide the LNG number on the MGO number for each of the studies, the numbers to compare fall out quite close, i.e., that WTT emissions for LNG are 24-35\% higher than for MGO; third, when dividing the LNG numbers on the HFO numbers, the relative differences are larger, which gives WTT emissions of LNG 37-93\% higher 
than for HFO, where the main source for the large variation is the difference in allocation principles for the refinery emissions.

With the Thinkstep (2019) [31] report being widely published, and their figures for LNG and MGO and the relationship between them being within the main range of values previously published, we used them for the WTW calculation in this study, i.e., for 18.5 for LNG and $14.4 \mathrm{~g}$ of $\mathrm{CO}_{2}$ eq per MJ for MGO. For VLSFO $<0.5 \% \mathrm{~S}$, there are few studies available, but as discussed above, $13.2 \mathrm{~g}$ of $\mathrm{CO}_{2}$ eq per MJ may be a realistic value. For HFO, there is a big gap between the Thinkstep global average and their Middle East values, mainly caused by their very high HFO values of 18.8 in North America compared to 11.7 in the Middle East and 13.4 in Europe. One of the arguments for scrubbers is that their HFO from 2020 will come from less-advanced refineries, which, overall, has a lower energy consumption per ton of output than the more advanced ones with their cracking, boiling in addition to a huge amount of hydrogen. For these reasons, we used the values by Lindstad (2019) [32] of $9.6 \mathrm{~g}$ of $\mathrm{CO}_{2}$ eq per MJ for HFO to fully exploit the maximum GHG reduction potential of using HFO in combination with a scrubber.

\subsection{Engine Performance Including Methane Slip}

HFO, VLSFO, and MGO are used in a traditional diesel engine, while the LNG is burnt in dual-fuel engines. For cruise ships and other ship types, which are using 4 stroke engines due to space and/or noise- restrictions, the dual-fuel engine concept implies injecting LNG under low pressure into the engine, which is comparable to the Otto cycle (petrol engine). The benefit of the Otto cycle is that it gives low $\mathrm{NO}_{\mathrm{x}}$ emissions and no additional treatment technologies are needed to fulfil IMO Tier III requirements. In addition, it comes at a much lower additional cost than the high-pressure dual-fuel solutions running according to the diesel cycle which are available for 2 stroke engines. For 2 stroke, both high-pressure (diesel) dual-fuel and low-pressure (Otto) dual-fuel solutions are available. Compared to the high-pressure (diesel) dual-fuel engine, the disadvantage with the low-pressure dual-fuel LNG engines is that the methane slip (caused by unburnt methane) is much higher both at high and low power. In addition, the thermal efficiency tends to be lower for the low-pressure (Otto) dual-fuel engines compared to the diesel option, due to the nature of the Otto process and the methane slip. For more insight into thermal efficiency of dual-fuel engines, see [44].

When the low-pressure dual-fuel engine is run purely on diesel, due to fuel prices or availability, the lower thermal efficiency also implies a higher fuel consumption compared to a conventional diesel engine. In this study, we therefore used $47 \%$ as the thermal efficiency for the pure diesel engine and $44 \%$ when the dual-fuel (Otto) LNG engine runs purely on diesel. This gives around $6 \%$ higher fuel consumption for the dual-fuel engine compared to the pure diesel engine. Assuming a higher thermal efficiency for diesel engines compared to dual-fuel (Otto) engines is in line with ICCT (2020) [9] and DNV-GL (2019) [35]. Both clearly state this for the 2 stroke, and we interpret it to be similar for the 4 stroke engine technology. This contrasts with Thinkstep (2019) [31], which has used a higher figure for LNG-fueled engines than for diesel-fueled engines, i.e., $49.5 \%$ versus $48 \%$ for 2 stroke and $46.5 \%$ versus $45 \%$ for 4 stroke. We cannot see that this is documented in the literature anywhere except that, at high power (maybe from $75 \%$ to $80 \%$ and upwards) at test bed, LNG might give a marginally better thermal efficiency. In contrast, at power from $75 \%$ and below, a diesel-based option gives better fuel utilization, and the difference increases when power outtake is reduced. One of the reasons for this is that the methane slip increases when the power is reduced, this both in percent and in gram per $\mathrm{kWh}$. For the fuel economy, methane slip equals increased fuel consumption, while, for the climate, it implies increased GHG emissions. With most ships today using around 50\% of installed power to operate at speeds $2-4$ knots or more below the design speed $[45,46]$, the disadvantage of dual-fuel (Otto) engines might therefore be even larger than reflected here.

Uncombusted methane gives a GHG impact 28-34 times higher per gram emitted than $\mathrm{CO}_{2}$ in a 100 year perspective [4]. That figure has increased steadily from 21 used in the Kyoto Protocol [2,39], to 25 in the Fourth and 30 in the Fifth IPCC Assessment Report [47], and finally to 36 now used by 
ICCT [9] in their study. In a shorter-term perspective such as 20 years, the warming impact of $\mathrm{CH}_{4}$ is 85 times larger per gram than $\mathrm{CO}_{2}$ [4]. In their study, Thinkstep (2019) [31] used testbed data from the $\mathrm{NO}_{\mathrm{x}}$ testing cycle for their estimate of uncombusted methane. The weakness of this approach is that the $\mathrm{NO}_{\mathrm{x}}$ test assumes that the engine operates at $75-100 \%$ power, $70 \%$ of the time, and at $25-50 \%$ the remaining $30 \%$ of the time. The explanation is that, when power decreases below $50 \%$, the methane slip in percent of fuel consumption increases [44,48], which is not representative for typical deep sea vessels nowadays operating at around $50 \%$ power load [30,46].

A more worrying fact is that, at these high loads represented by the $\mathrm{NO}_{\mathrm{x}}$ testing cycle, the uncombusted methane for LNG is lowest. In addition, test-bed values tend to be lower than when measurements are performed based on the same testing cycle at vessels at sea. This is well documented in the SINTEF study from 2017 [48]: GHG and $N O_{x}$ emissions from gas fuelled EnginesMapping, verification, reduction technologies authored by Stenersen and Thonstad, which is publicly available through the Norwegian $\mathrm{NO}_{x}$-fund homepage.

Comparing the results from the SINTEF report (2017) [48] with Thinkstep (2019) [31] for 4 stroke engines, we get: low pressure dual fuel (LP-DF-LNG) $=5.3 \mathrm{~g}$ per $\mathrm{kWh}$ versus Thinkstep $=3.9 \mathrm{~g}$ per kWh. Here, ICCT (2020) [9] has used $5.5 \mathrm{~g}$ of uncombusted methane.

In the present study, we investigated two scenarios, of which the best case for LNG is based on test-bed measurements of methane slip, and taking into account that thermal engine efficiency for dual-fuel (Otto) LNG engines can be nearly equal to the pure diesel engine, apart from the methane slip. For the test-bed case, $3.9 \mathrm{~g}$ per kWh of methane slip was used. This is an average estimate based on the fact that real methane slip on ships in operation is higher than in a test bed at the laboratory, i.e., $5.3 \mathrm{~g}$ per $\mathrm{kWh}$, as recommended by [48]. However, even this value might underestimate the real methane slip, since most of the global fleet today operates at around $50 \%$ power $[30,46]$ and not at around $70 \%$ given by the $\mathrm{NO}_{\mathrm{x}}$ test cycle. The explanation is that, when power decreases below $50 \%$, the methane slip in $\%$ of fuel consumption increases [44,48].

\subsection{Well-to-Wake Emissions (WTW)}

Table 3 shows the WTW emissions for the seven assessed fuel options based on the WTT emissions, the engine performance and methane slip as described in the two previous sections. Here, the first column gives either an input value or a calculated value, categorized as follows:

1. The $\mathrm{CO}_{2}$ emissions factors and the low calorific value for each fuel.

2. The GWP factors for methane.

3. The thermal engine efficiency.

4. The specific fuel oil consumption (SFOC) calculated based on 1 and 2 .

5. The methane slips.

6. TTW emissions are calculated based on fuel consumption and $\mathrm{CO}_{2}$ emission factors.

7. WTT emissions calculated based on gram per MJ and the thermal efficiency for GWP100 and for GWP20.

8. WTW emissions are given by adding up WTT with TTW emissions.

9. WTW emissions in \% of MGO are found by dividing WTW for each option on the MGO value both for GWP100 and for GWP20. 
Table 3. Well-to-wake (WTW) $\mathrm{CO}_{2}$ eq emissions per $\mathrm{kWh}$ as a function of fuel and engine.

\begin{tabular}{|c|c|c|c|c|c|c|c|c|}
\hline \multicolumn{2}{|c|}{$\begin{array}{l}4 \text { Stroke Medium-Speed Engines. } \\
\text { Comparing Pure Diesel Engines and } \\
\text { Dual-Fuel (Otto) LNG Engines }\end{array}$} & $\begin{array}{l}\text { HFO \& } \\
\text { Scrubber }\end{array}$ & VLSFO & MGO & $\begin{array}{l}\text { LNG-DF } \\
\text { (Otto-Engine)-Test } \\
\text { Bed }\end{array}$ & $\begin{array}{c}\text { LNG-DF } \\
\text { (Otto-Engine) }\end{array}$ & $\begin{array}{c}\text { VLSFO } \\
\text { (Otto-Engine) }\end{array}$ & $\begin{array}{c}\text { MGO } \\
\text { (Otto-Engine) }\end{array}$ \\
\hline \multicolumn{2}{|c|}{$\mathrm{CO}_{2}$ emission factors } & 3.114 & 3.176 & 3.206 & 2.75 & 2.75 & 3.176 & 3.206 \\
\hline Lower calorific value & $\mathrm{MJ} / \mathrm{kg}$ & 40.2 & 41.0 & 42.7 & 49.2 & 49.2 & 41 & 42.7 \\
\hline \multirow{2}{*}{\multicolumn{2}{|c|}{$\begin{array}{l}\mathrm{CH}_{4}-\mathrm{GWP} 100\left(\mathrm{CO}_{2} \mathrm{eq}\right) \\
\mathrm{CH}_{4}-\mathrm{GWP} 20\left(\mathrm{CO}_{2} \mathrm{eq}\right)\end{array}$}} & & & & 30 & 30 & & \\
\hline & & & & & 85 & 85 & & \\
\hline \multicolumn{2}{|l|}{ Thermal engine efficiency } & $47 \%$ & $47 \%$ & $47 \%$ & $45.8 \%$ & $45 \%$ & $44 \%$ & $44 \%$ \\
\hline \multirow{2}{*}{\multicolumn{2}{|c|}{$\begin{array}{l}\text { Thermal engine efficiency } \\
\text { for pure diesel engine } \\
\text { Thermal engine efficiency } \\
\text { compared to pure diesel } \\
\text { engine }\end{array}$}} & & & & $47 \%$ & $47 \%$ & $47 \%$ & $47 \%$ \\
\hline & & & & & $97 \%$ & $96 \%$ & $94 \%$ & $94 \%$ \\
\hline \multirow{2}{*}{$\begin{array}{c}\text { Fuel consumption (SFOC) } \\
\text { Methane Slip }\end{array}$} & Gram $/ \mathrm{kWh}$ & 191 & 187 & 179.5 & 159.9 & 162.9 & 200 & 192.1 \\
\hline & $\mathrm{Gram} / \mathrm{kWh}$ & & & & 3.9 & 5.3 & & \\
\hline \multirow{2}{*}{$\begin{array}{l}\text { TTW-GWP100 } \mathrm{CO}_{2} \text { eq } \\
\text { TTW-GWP20 } \mathrm{CO}_{2} \text { eq }\end{array}$} & Gram/kWh & 595 & 595 & 576 & 556 & 608 & 638 & 618 \\
\hline & $\mathrm{Gram} / \mathrm{kWh}$ & 595 & 595 & 576 & 771 & 899 & 638 & 618 \\
\hline \multirow[t]{2}{*}{ WTT-GWP100 $\mathrm{CO}_{2} \mathrm{eq}$} & Gram/MJ & 9.6 & 13.2 & 14.4 & 18.5 & 18.5 & 13.2 & 14.4 \\
\hline & Gram $/ \mathrm{kWh}$ & 74 & 101 & 110 & 145 & 148 & 108 & 118 \\
\hline \multirow[t]{2}{*}{ WTT-GWP20-CO $\mathrm{CO}_{2} \mathrm{eq}$} & Gram/MJ & 14.1 & 19.6 & 20.8 & 27.9 & 27.9 & 19.6 & 20.8 \\
\hline & Gram/kWh & 108 & 150 & 159 & 219 & 223 & 160 & 170 \\
\hline \multirow{2}{*}{$\begin{array}{l}\text { WTW-GWP100- } \mathrm{CO}_{2} \text { eq } \\
\text { WTW-GWP20-CO } \mathrm{CO}_{2} \text { eq }\end{array}$} & Gram/kWh & 668 & 696 & 686 & 701 & 756 & 746 & 736 \\
\hline & Gram/kWh & 703 & 745 & 735 & 990 & 1122 & 798 & 789 \\
\hline \multirow{2}{*}{$\begin{array}{l}\text { WTW GWP100 in \% of } \\
\text { MGO } \\
\text { WTW GWP20 in \% of } \\
\text { MGO }\end{array}$} & $\%$ & $97 \%$ & $101 \%$ & $100 \%$ & $102 \%$ & $110 \%$ & $109 \%$ & $107 \%$ \\
\hline & $\%$ & $96 \%$ & $101 \%$ & $100 \%$ & $135 \%$ & $153 \%$ & $109 \%$ & $107 \%$ \\
\hline
\end{tabular}

The main observations from Table 3 are:

- First, LNG with a short-term horizon (GWP20) increases GHG emissions by 35-53\% compared to the existing diesel options.

- Second, with a long-time horizon (GWP100), the increase is more modest, i.e., up to $10 \%$, but LNG still gives no GHG emissions reduction, even in GWP100.

- Third, when the dual-fuel engines run purely on MGO or VLSFO, the GHG emissions increase by $7-9 \%$ compared to when diesel is burnt on a pure diesel engine. The reason is the lower thermal efficiency of the Otto dual-fuel engine compared to the pure diesel engine.

- Fourth, the potential GHG reduction with scrubbers are up to $2-4 \%$ compared to MGO, if we assume that HFO is the bottom of the barrel from standard oil refineries.

These results are visualized in Figures 2 and 3, displaying values for GWP20 and GWP100, respectively. The figures show gram per $\mathrm{CO}_{2}$ eq per $\mathrm{kWh}$ for WTT, TTW, and methane slip for each of the investigated fuel and engine combinations. Moreover, the vertical dashed line shows the baseline value, i.e., the WTW of MGO, and the green number on the right side shows the value in \% of the MGO baseline. 
WTW with Diesel \& Dual fuel (Otto) 4-stroke engines, in gram $\mathrm{CO}_{2}$ eq. per $\mathrm{kWh}-\mathrm{GWP} 20$

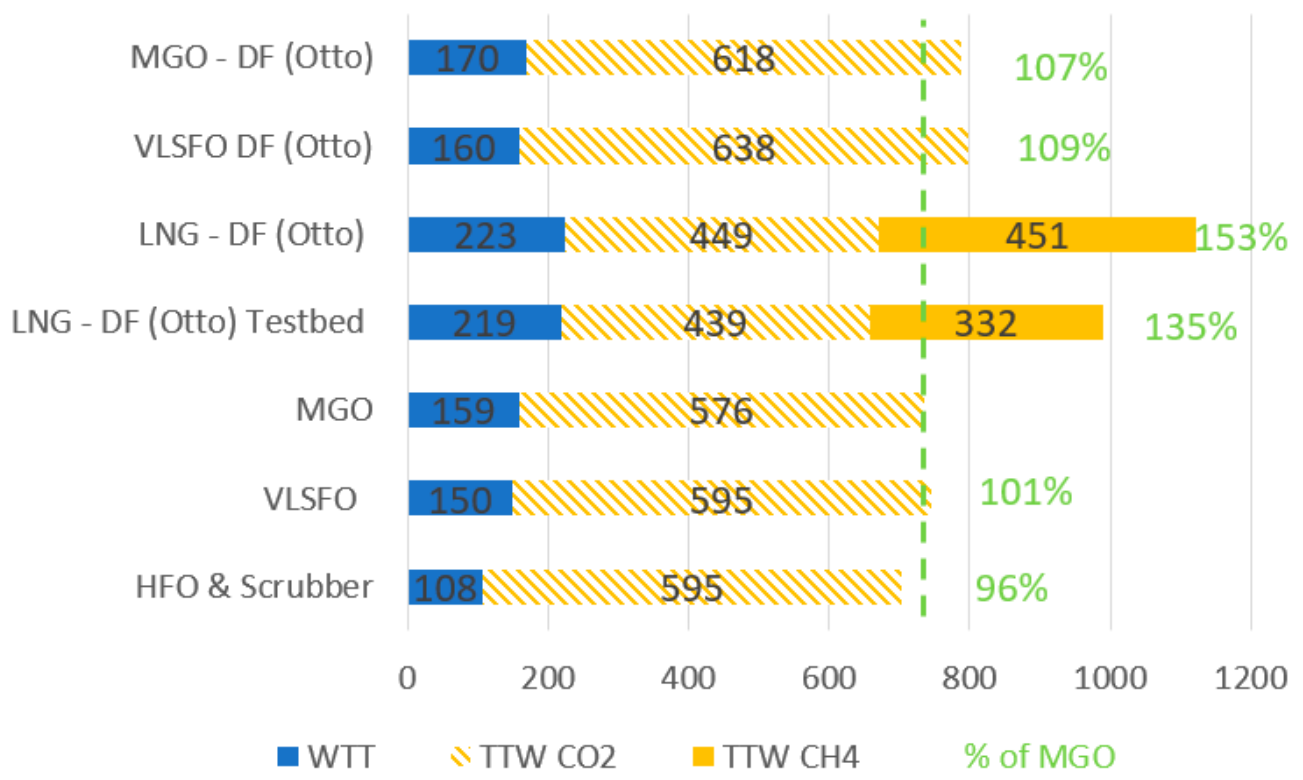

Figure 2. Well-to-wake (WTW) $\mathrm{CO}_{2}$ eq emissions per $\mathrm{kWh}$ as a function of fuel and engine, GWP20.

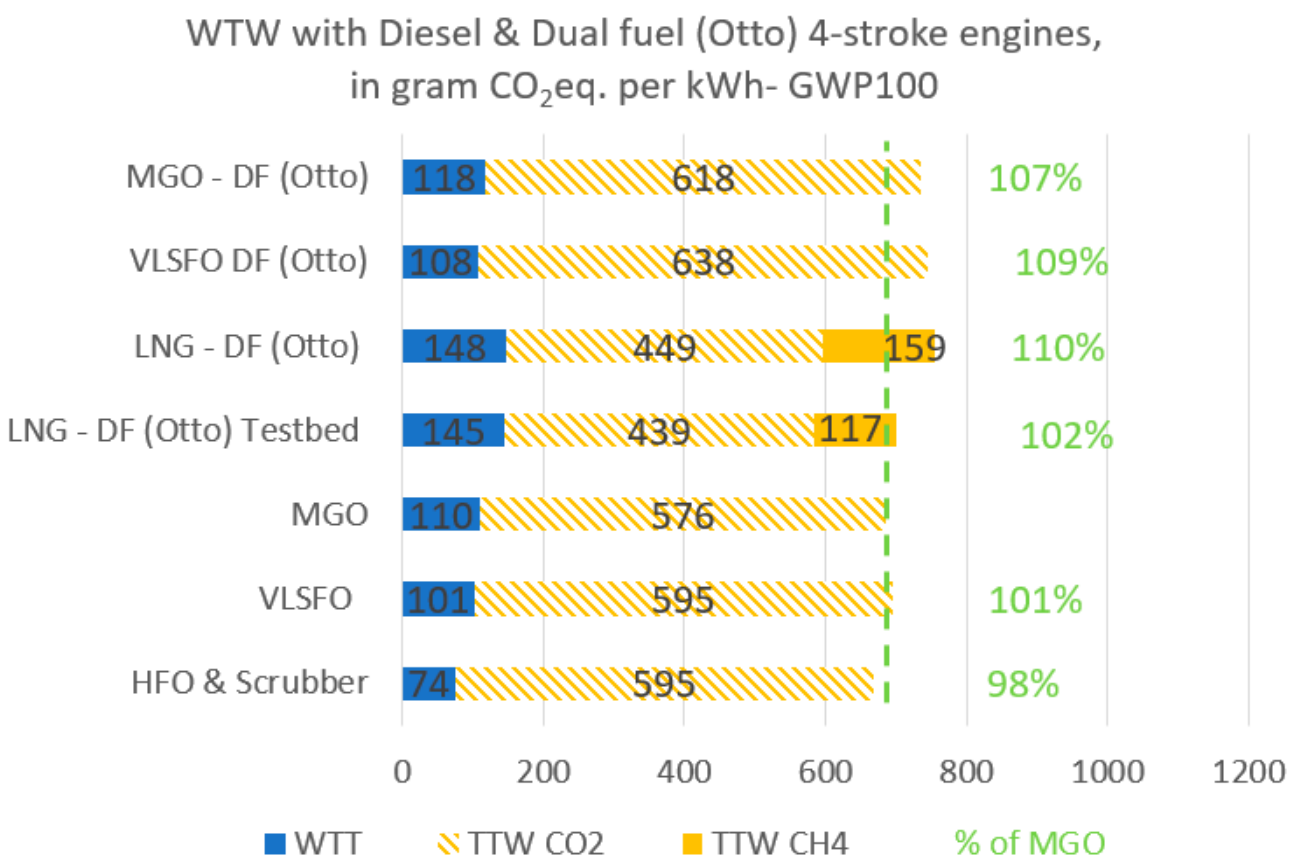

Figure 3. Well-to-wake (WTW) $\mathrm{CO}_{2}$ eq emissions per $\mathrm{kWh}$ as a function of fuel and engine, GWP100.

The main observation is that the WTW emissions increase with dual-fuel (Otto) engines, both when fueled on LNG, and on MGO or VLSFO both for GWP20 and GWP100.

\section{Comparing the Results with Previous Studies}

Table 4 compares the results of this study with previous studies. The first column is used to give the reference to the study; the second and the third column are used for the WTW emissions relative to MGO found by each study with GWP20 and GWP100. 
Table 4. Comparing the results of the present study with previous studies.

\begin{tabular}{ccc}
\hline Comparing Results & $\begin{array}{c}\text { Dual-Fuel (Otto) LNG } \\
\text { GWP20 }\end{array}$ & $\begin{array}{c}\text { Stroke Engines } \\
\text { GWP100 }\end{array}$ \\
\hline DNV-GL (2019) [35] Lowest & & $90 \%$ \\
DNV-GL (2019) [35] Highest & & $100 \%$ \\
Thinkstep (2019) [31] & $123 \%$ & $96 \%$ \\
This study, test bed & $135 \%$ & $102 \%$ \\
Lindstad (2019) [32] & $146 \%$ & $106 \%$ \\
This study & $153 \%$ & $110 \%$ \\
ICCT (2020) [9] & $162 \%$ & $116 \%$ \\
\hline
\end{tabular}

The main observations are:

- All studies that have investigated GWP20 confirm that LNG and dual-fuel (Otto) 4 stroke engines increase GHG emissions within a 20 year time horizon.

- For a 100 year time horizon, the figures from DNV-GL (2019) [35] and Thinkstep (2019) [31] indicate a small GHG reduction with LNG, i.e., 0-10\%. This contrasts with ICCT (2020) [9], which indicates that GHG emissions with LNG could increase by $16 \%$, with this study indicating an increase of up to $10 \%$, and with Lindstad (2019) reporting a GHG emission increase of $6 \%$.

To better understand and explain these differences, we used the same spreadsheet model as used in Table 3. Here in Table 5, the last column is used to display the differences in input values and assumptions made by each individual study.

Table 5. Explaining why previous studies have shown very different GHG impacts.

\begin{tabular}{|c|c|c|c|c|c|}
\hline \multicolumn{2}{|c|}{$\begin{array}{l}4 \text { Stroke Medium-Speed Engines. } \\
\text { Comparing Pure Diesel Engines and } \\
\text { Dual-Fuel (Otto) LNG Engines }\end{array}$} & \multirow{2}{*}{$\begin{array}{c}\text { MGO (Diesel } \\
\text { Engine) }\end{array}$} & \multirow{2}{*}{$\begin{array}{c}\text { LNG-DF } \\
\text { (Otto-Engine) - } \\
\text { Test Bed } \\
2.75 \\
49.2\end{array}$} & \multirow{2}{*}{$\begin{array}{c}\begin{array}{c}\text { LNG-DF } \\
\text { (Otto-Engine) }\end{array} \\
2.75 \\
49.2\end{array}$} & \multirow{2}{*}{$\begin{array}{l}\text { Why Previous Studies Have Shown Very } \\
\text { Different GHG Impacts } \\
\text { LNG values in the range of } 49.2-50 \mathrm{MJ} / \mathrm{kg}\end{array}$} \\
\hline $\mathrm{CO}_{2}$ emission factors & & & & & \\
\hline $\mathrm{CH}_{4}-\mathrm{GWP} 100\left(\mathrm{CO}_{2} \mathrm{eq}\right)$ & & & 30 & 30 & \\
\hline $\mathrm{CH}_{4}-\mathrm{GWP} 20\left(\mathrm{CO}_{2} \mathrm{eq}\right)$ & & & 85 & 85 & \\
\hline \multirow{2}{*}{$\begin{array}{l}\text { Thermal engine efficiency } \\
\text { Thermal engine efficiency } \\
\text { compared to pure diesel } \\
\text { engine }\end{array}$} & & \multirow[t]{2}{*}{$47 \%$} & $45.8 \%$ & $45 \%$ & \multirow{2}{*}{$\begin{array}{l}\text { Thermal efficiency for LNG and dual-fuel } \\
\text { engine with range going from } 94 \text { to } 103 \% \text { of } \\
\text { pure diesel engine }\end{array}$} \\
\hline & & & $97 \%$ & $96 \%$ & \\
\hline \multirow{2}{*}{$\begin{array}{c}\text { Fuel consumption (SFOC) } \\
\text { Methane Slip }\end{array}$} & Gram/kWh & 179.5 & 159.9 & 162.9 & \multirow{2}{*}{$\begin{array}{l}\text { Methane slip values in the } \\
\text { range of 3.9-5.5 }\end{array}$} \\
\hline & Gram/kWh & & 3.9 & 5.3 & \\
\hline \multirow{2}{*}{$\begin{array}{l}\text { TTW - GWP100 } \mathrm{CO}_{2} \mathrm{eq} \\
\text { TTW - GWP20 } \mathrm{CO}_{2} \mathrm{eq}\end{array}$} & Gram/kWh & 575 & 545 & 608 & \\
\hline & Gram/kWh & 575 & 760 & 899 & \\
\hline WTT - GWP20 - $\mathrm{CO}_{2} \mathrm{eq}$ & $\mathrm{Gram} / \mathrm{kWh}$ & 159 & 219 & 223 & GWP20 not covered by all studies \\
\hline \multirow{2}{*}{$\begin{array}{l}\text { WTW - GWP100 - } \mathrm{CO}_{2} \mathrm{eq} \\
\text { WTW - GWP20 - } \mathrm{CO}_{2} \mathrm{eq}\end{array}$} & Gram/kWh & 686 & 701 & 756 & \\
\hline & Gram $/ \mathrm{kWh}$ & 735 & 990 & 1122 & \\
\hline \multirow{2}{*}{$\begin{array}{l}\text { WTW GWP100 in \% of } \\
\text { MGO } \\
\text { WTW GWP20 in \% of } \\
\text { MGO }\end{array}$} & $\%$ & $100 \%$ & $102 \%$ & $110 \%$ & \\
\hline & $\%$ & $100 \%$ & $135 \%$ & $153 \%$ & \\
\hline
\end{tabular}

As we can see from the table, with these large differences in input values, it is hardly surprising that previous studies have shown very different results. Moreover, the following observations can be made, in comparison with the present study:

- DNV-GL (2019) [35] have used a $\mathrm{CH}_{4}$ factor of 21 [3,39] instead of 30 [4] for GWP100 and WTT emissions, which are around 50\% lower than the typical values found by studies of WTT emissions from producing LNG, as shown in Table 1. 
- Thinkstep (2019) [31] has used a higher thermal efficiency for dual-fuel gas operations than for diesel. Furthermore, they have assumed (according to our interpretation) that all ships operate in ECAs according to the $\mathrm{NO}_{x}$ Tier III requirements, which increases GHG emissions for conventional fuels due to the urea consumption required by the SCR (selective catalytic reduction) process to reduce the $\mathrm{NO}_{x}$ content in the exhaust gas. This, despite that: first, $\mathrm{NO}_{x}$ Tier III is only applicable to newbuilt ships after 2016/2021; second, newbuilt ships that generally have advanced engine control systems will operate in Tier II mode outside the ECAs to save fuel; third, the ECAs cover only a small part of the global oceans.

- ICCT (2020) [9] has used a higher $\mathrm{CH}_{4}$ factor, i.e., 36 instead of 30 for GWP100. It has also applied methane slip figures that are slightly higher than manufacturers' test bed figures, and a higher lower calorific value for $\mathrm{CH}_{4}$, i.e., 50 instead of 49.2 .

To make fair and square comparisons, GHG assessment of WTW emissions from alternative fuels and engines needs to be based on the following conditions and assumptions:

- Acknowledged WTT GHG emissions levels reported in published studies for production of LNG or conventional fuels, or both, and not on best-case assumption for one of the assessed fuels.

- The most recent knowledge published by IPCC through their Assessment Reports regarding GWP factors for the different GHG.

- Well-proven and accepted thermal efficiency for different 4 stroke engines.

- That the existing ocean-going fleet built up to 2016 will operate according to the $\mathrm{NO}_{\mathrm{x}}$ Tier II rules with no need for any $\mathrm{NO}_{\mathrm{x}}$ after treatment of the exhaust gas even for conventional fuels.

- That new ocean-going vessels will use today's advanced engine control systems to operate in $\mathrm{NO}_{\mathrm{x}}$ Tier II mode outside the ECAs and operate in $\mathrm{NO}_{\mathrm{x}}$ Tier III mode only when in ECAs (with use of Urea in the SCR process or other $\mathrm{NO}_{x}$ reduction means).

Based on these premises, the results indicate that LNG with 4 stroke dual fuel (Otto) will increase the cruise sector's GHG emissions compared to conventional fuels (MGO, HFO and Scrubber, and VLSFO).

\section{Discussion and Conclusions}

With climate change potentially being the largest threat to mankind [10], it is important that decisions with an impact on future GHG emissions are based on best available knowledge within a sector and across sectors. The contributions from this paper are:

- Comparable well-to-tank (WTT) GHG estimates, for LNG and conventional fuels.

- Transparent calculations of well-to-wake (WTW) GHG emissions for the investigated fuels.

- A transparent comparison of the results of this study with previous studies.

- Results indicating that increased use of dual-fuel (Otto) LNG engines (which are the current option for cruise vessels and other vessels using 4 stroke engines) will increase GHG emissions compared to conventional fuels (MGO, HFO \& Scrubber, and VLSFO).

In this study, we have not investigated the cost aspect, but according to Lindstad et al. [8], the typical additional cost for the LNG dual-fuel (Otto) engines including the fuel tanks for ships with 25-50 MW engine capacity installed will be 15-30 MUSD. With the cost of a new cruise ship starting from some hundred million USD and upward, this is a small cost for fulfilling IMO's air emission rules. In comparison, a scrubber installation to enable use of HFO might come at half of this cost [8]. However, that gives no reduction in EEDI. This contrasts with LNG applied on a new ship, which automatically gives $25 \%$ reduction of the ships' EEDI value, compared to when using conventional fuels such as MGO. Apart from major design speed reductions, no other measures give similar EEDI improvements for such a small cost [30]. Moreover, with LNG becoming cheaper than HFO in some regions globally [9], and its good public perception compared to conventional fuels, nobody should 
be surprised if a growing number of newbuilt cruise ships are delivered with LNG dual-fuel engines based on using LNG as their main fuel.

This also applies for the whole fleet of vessels using 4 stroke diesel engines: the combination of lower LNG fuel prices, the relatively low cost of the LNG Otto solution, and the stricter EEDI, will be a strong incentive for building new ships with LNG dual-fuel Otto engines.

If the maritime sector shall fulfil its GHG target, real reductions instead of paper savings through paragraph ships are required. To solve this, methane needs to be included in the IMO EEDI formula. This to reward LNG engine technologies that have nearly no methane slip, i.e., high-pressure dual-fuel (diesel) LNG engines. This technology is already available and in use for the 2 stroke engine segment, where it delivers 15\% GHG reductions of WTW emissions for ships with dual-fuel (diesel) LNG engines [8]. Therefore, to fully take advantage of LNG as a potential transition fuel, there is a need for development of dual-fuel (diesel) LNG engines also for the 4 stroke engine market. Including $\mathrm{CH}_{4}$ in the EEDI will also incentivize manufacturers of Otto LNG engines to do whatever they can to minimize the uncombusted methane within the full boundaries of the Otto LNG process or through after treatment of exhaust gas.

Author Contributions: Conceptualization, E.L.; Methodology, E.L.; Software, E.L., A.R.; Validation, E.L., A.R.; Formal analysis, E.L.; Investigation, E.L., A.R.; resources, E.L.; Writing—original draft preparation, E.L.; Writing-review and editing, E.L., A.R.; Visualization, E.L., A.R.; Funding acquisition, E.L. All authors have read and agreed to the published version of the manuscript.

Funding: This study has been financially supported by the Norwegian Research Council project (Norges Forskningsråd) SFI Smart Maritime project number 237917.

Conflicts of Interest: There is no conflict of interest in publishing this paper.

\section{References}

1. IMO (Ed.) Protocol of 1997 to Amend MARPOL 73/78: Annex VI of MARPOL 73/78: Regulations for the Prevention of Air Pollution from Ships, and Final Act of the 1997 MARPOL Conference, and the Technical Code on Control of Emission of Nitrogen Oxides from Marine Diesel Engines; International Maritime Organization (IMO): London, UK, 1997; p. 150.

2. UN. Kyoto Protocol to the United Nations Framework Convention on Climate Change; COP3: Kyoto, Japan, 1997.

3. IMO (Ed.) Resolution MEPC 203 (62) (Adopted on 15 July 2011) Amendments to the Annex of the Protocol of 1997 to Amend the International Convention for the Prevention of Pollution from Ships, 1973, as Modified by the Protocol of 1978 Relating There to (Inclusion of Regulations on Energy Efficiency for Ships in MARPOL Annex VI); IMO: London, UK, 2011.

4. IPCC. Climate Change 2014: Impacts, Adaptation, and Vulnerability. Part A: Global and Sectoral Aspects. Contribution of Working Group II to the Fifth Assessment Report of the Intergovernmental Panel on Climate Change; Field, C.B., Barros, V.R., Dokken, D.J., Mach, K.J., Mastrandrea, M.D., Bilir, T.E., Chatterjee, M., Ebi, K.L., Estrada, Y.O., Genova, R.C., et al., Eds.; IPCC: Cambridge, UK; New York, NY, USA, 2014; p. 1132.

5. Shine, K.P. The global warming potential-the need for an interdisciplinary retrial. Clim. Chang. 2009, 96, 467-472. [CrossRef]

6. Balcombe, P.; Speirs, J.F.; Brandon, N.P.; Hawkes, A.D. Methane emissions: Choosing the right climate metric and time horizon. Environ. Sci. Process. Impacts 2018, 20, 1323-1339. [CrossRef] [PubMed]

7. IPCC. Climate Change 2013: The Physical Science Basis. Contribution of Working Group I to the Fifth Assessment Report of the Intergovernmental Panel on Climate Change; Stocker, T.F.D., Qin, G.-K., Plattner, M., Tignor, S.K., Allen, J., Boschung, A., Nauels, Y., Xia, V.B., Midgley, P.M., Eds.; IPCC: Cambridge, UK; New York, NY, USA, 2013; p. 1535.

8. Lindstad, E.; Eskeland, G.; Valland, A. The Importance of Encouraging and Rewarding Best Engine Technologies for Achieving Maritime GHG Reduction; 2020; (Unpublished; Manuscript in Preparation).

9. The Climate Implications of Using LNG as a Marine Fuel; ICCT, International Council on Clean Transportation, 2020. Available online: https://theicct.org/publications/climate-impacts-LNG-marine-fuel-2020 (accessed on 7 February 2020). 
10. UN (Ed.) United Nations Framework Convention on Climate Change; Paris Agreement: FCCC/CP/2015/L.9/Rev.1.; United Nations: Paris, France, 2015.

11. Campling, P.; Janssen, L.; Vanherle, K.; Cofala, J.; Heyes, C.; Sander, R. Specific Evaluation of Emissions from Shipping Including Assessment for the Establishment of Possible New Emission Control Areas in European Seas; Flemish Institute for Technological Research (VITO): Mol, Belgium, 2013; p. 34.

12. Johansson, L.; Jalkanen, J.P.; Kalli, J.; Kukkonen, J. The evolution of shipping emissions and the costs of regulation changes in the northern EU area. Atmos. Chem. Phys. 2013, 13, 11375-11389. [CrossRef]

13. Brynolf, S.; Magnusson, M.; Fridell, E.; Andersson, K. Compliance possibilities for the future ECA regulations through the use of abatement technologies or change of fuels. Transp. Res. Part D Transp. Environ. 2014, 28, 6-18. [CrossRef]

14. Jiang, L.; Kronbak, J.; Christensen, L.P. The costs and benefits of sulphur reduction measures: Sulphur scrubbers versus marine gas oil. Transp. Res. Part D Transp. Environ. 2014, 28, 19-27. [CrossRef]

15. Acciaro, M. Real option analysis for environmental compliance: LNG and emission control areas. Transp. Res. Part D Transp. Environ. 2014, 28, 41-50. [CrossRef]

16. Lindstad, E.; Eskeland, G.S.; Psaraftis, H.; Sandaas, I.; Strømman, A.H. Maritime shipping and emissions: A three-layered, damage-based approach. Ocean Eng. 2015, 110, 94-101. [CrossRef]

17. Lindstad, E.; Sandaas, I.; Strømman, A.H. Assessment of cost as a function of abatement options in maritime emission control areas. Transp. Res. Part D Transp. Environ. 2015, 38, 41-48. [CrossRef]

18. Lindstad, E.; Eskeland, G.S. Environmental regulations in shipping: Policies leaning towards globalization of scrubbers deserve scrutiny. Transp. Res. Part D Transp. Environ. 2016, 47, 67-76. [CrossRef]

19. Øberg, M.M. Life Cycle Assessment of Fuel Choices for Marine Vessels; NTNU, Norwegian University of Science and Technology: Trondheim, Norway, 2013.

20. Silva, M. Life Cycle Assessment of Marine Fuel Production; NTNU, Norwegian University of Science and Technology: Trondheim, Norway, 2017.

21. Buhaug, Ø.; Corbett, J.J.; Endresen, Ø.; Eyring, V.; Faber, J.; Hanayama, S.; Lee, D.S.; Lee, D.; Lindstad, H.; Markowska, A.Z.; et al. Second IMO GHG Study 2009; International Maritime Organization (IMO): London, UK, 2009.

22. Bengtsson, S.; Andersson, K.; Fridell, E. Life Cycle Assessment of Marine Fuels: A Comparative Study of Four Fossil Fuels for Marine Propulsion; Chalmers University of Technology, Department of Shipping and Marine Technology, Division of Sustainable Ship Propulsion: Gothenburg, Sweden, 2011.

23. Verbeek, R.; Kadijk, G.; van Mensch, P.; Wulffers, C.; van den Beemt, B.; Fraga, F. 2011 Environmental and Economic Aspects of Using LNG as a Fuel for Shipping in The Netherlands; TNO Report TNO-RPT-2011-00166; TNO: Delft, The Netherlands, 2011; p. 48.

24. Chryssakis, C.; Stahl, S. Well-To-Propeller Analysis of Alternative Fuels for Maritime Applications. In Proceedings of the CIMAC 2013, Shanghai, China, 13-17 May 2013.

25. Edwards, R.; Larive, J.-F.; Rickeard, D.; Weindorf, W.; Godwin, S.; Hass, H.; Krasenbrink, A.; Lonza, L.; Maas, H.; Nelson, R.; et al. WELL-TO-TANK Report Version 4.a: JEC WELL-TO-WHEELS ANALYSIS; JRC, EUCAR and CONCAWE; Publications Office of the European Union: Luxembourg, 2014.

26. Bengtsson, S.K.; Fridell, E.; Andersson, K.E. Fuels for short sea shipping: A comparative assessment with focus on environmental impact. Proc. Inst. Mech. Eng. Part M J. Eng. Marit. Environ. 2014, 228, 44-54. [CrossRef]

27. Brynolf, S.; Kuvalekar, S.; Andersson, K. Life Cycle Assessment of Methanol and Dimethyl Ether (DME) as Marine Fuels; Report 2014; Department of Shipping and Marine Technology, Chalmers University of Technology: Göteborg, Sweden, 2014.

28. Verbeek, R.; Verbeek, M. LNG for Trucks and Ships: Fact Analysis Review of Pollutant and GHG Emissions; TNO: Delft, The Netherlands, 14 February 2015; p. 70.

29. Bouman, E.A.; Lindstad, E.; Rialland, A.I.; Strømman, A.H. State-of-the-art technologies, measures, and potential for reducing GHG emissions from shipping-A review. Transp. Res. Part D Transp. Environ. 2017, 52, 408-421. [CrossRef]

30. Lindstad, E.; Bø, T.I. Potential power setups, fuels and hull designs capable of satisfying future EEDI requirements. Transp. Res. Part D Transp. Environ. 2018, 63, 276-290. [CrossRef] 
31. Thinkstep. Life Cycle GHG Emission Study on the Use of LNG as Marine Fuel. Available online: https://www.thinkstep.com/content/life-cycle-ghg-emission-study-use-lng-marine-fuel-1 (accessed on 30 November 2019).

32. Lindstad, E. Increased Use of LNG Might Not Reduce Maritime GHG Emissions at all-June 2019. Transport \& Environment's (T\&E). Available online: https://www.transportenvironment.org/sites/te/files/ publications/2019_06_Dr_Elizabeth_Lindstad_commentary_LNG_maritime_GHG_emissions.pdf (accessed on 1 September 2019).

33. Thinkstep. Available online: https://www.gabi-software.com (accessed on 30 June 2019).

34. Argonne. GREET: Greenhouse Gases, Regulated Emissions, and Energy Use in Transportation (GREET) Model; Argonne National Laboratory: Lemont, IL, USA, 2018.

35. DNV-GL. Assessment of Selected Alternative Fuels and Technologies. p. 56 . Available online: https://www.dnvgl.com/maritime/publications/alternative-fuel-assessment-download.html (accessed on 30 November 2019).

36. DNV-GL. Maritime Forecast to 2050, in ENERGY TRANSITION OUTLOOK 2019. Available online: https://eto.dnvgl.com/2019/Maritime/ (accessed on 30 November 2019).

37. Verbeek, R.; Lingterink, R.; Meulenbrugge, J.; Kooneef, G.; Kroon, P.; de Wilde, H.; Kampman, B.; Croezen, H.; Aamink, S.; Verbeek, R.; et al. 2013 Natural Gas in Transport-An Assessment of Different Routes, TNO Report 4.818.1; TNO: Delft, The Netherlands, 2013; p. 172.

38. NGVA. Greenhouse Gas Intensity of Natural Gas, Prepared by Thinkstep; NGVA Europe (European Natural \& bio Gas Vehicle Association): Brussels, Belgium, 2017.

39. EXERGIA; E3M-Lab; COWI. Study on Actual GHG Data for Diesel, Petrol, Kerosene and Natural Gas-Final Report, EXERGIA S.A.-E3M-Lab-COWI A/S, Members of COWI Consortium, Prepared for European Commission DG ENERGY; DG Energy: Brussels, Belgium, 2015; p. 549.

40. Skone, T.J.; Cooney, G.; Jamieson, M.; Littlefield, J.; Marriott, J. Life Cycle Greenhouse Gas Perspective on Exporting Liquefied Natural Gas from the United States. Available online: https://www.energy.gov/fe/ downloads/life-cycle-greenhouse-gas-perspective-exporting-liquefied-natural-gas-united-states (accessed on 29 May 2014).

41. El-Houjeiri, H.; Monfort, J.-C.; Bouchard, J.; Przesmitzki, S. Life Cycle Assessment of Greenhouse Gas Emissions from Marine Fuels: A Case Study of Saudi Crude Oil versus Natural Gas in Different Global Regions. J. Ind. Ecol. 2018, 23, 374-388. [CrossRef]

42. Shell. The Bunker Fuels Challenge: How Should You Respond? Technology Trends to Watch. Available online: http://www.shell.com/business-customers/global-solutions/industry-focus/the-bunkerfuels-challenge.html (accessed on 30 November 2016).

43. Lindstad, H.E.; Rehn, C.F.; Eskeland, G.S. Sulphur abatement globally in maritime shipping. Transp. Res. Part D Transp. Environ. 2017, 57, 303-313. [CrossRef]

44. Ushakov, S.; Stenersen, D.; Einang, P.M. Methane slip from gas fuelled ships: A comprehensive summary based on measurement data. J. Mar. Sci. Technol. 2019, 24, 1308-1325. [CrossRef]

45. Smith, T.W.P.; Jalkanen, J.P.; Anderson, B.A.; Corbett, J.J.; Faber, J.; Hanayama, S.; O’Keeffe, E.; Parker, S.; Johansson, L.; Aldous, L.; et al. The Third IMO GHG Study; International Maritime Organization (IMO): London, UK, 2014.

46. Fairplay. Pace Race—Slow Steaming Not Necessarily a Sulphur Cap Saviour; Fairplay Magazine: London, UK, 2018; pp. 24-26.

47. IPCC. IPCC, Climate Change 2007: Synthesis Report. Contribution of Working Groups I, II and III to the Fourth Assessment Report of the Intergovernmental Panel on Climate Change; Pachauri, R.K., Reisinger, A., Eds.; IPCC: Geneva, Switzerland, 2007; p. 104.

48. Stenersen, D.; Thonstad, O. GHG and NOx Emissions from Gas Fuelled Engines-Mapping, Verification, Reduction Technologies; OC2017 F-108; SINTEF Ocean: Trondhein, Norway, 2017.

(C) 2020 by the authors. Licensee MDPI, Basel, Switzerland. This article is an open access article distributed under the terms and conditions of the Creative Commons Attribution (CC BY) license (http://creativecommons.org/licenses/by/4.0/). 